\title{
RECOMENDANDO OBJETOS DE APRENDIZAGEM BASEADO EM COMPETÊNCIAS EM EAD
}

\author{
Silvio César Cazella * \\ Ketia Kellen da Silva** \\ Patricia Bhear ${ }^{* * *}$ \\ Daisy Schneider**** \\ Rodrigo Freitas ${ }^{* * * * *}$
}

\begin{abstract}
Resumo. Este artigo descreve um modelo para recomendação de objetos de aprendizagem baseado em competência em Educação a Distância. Trata-se de um projeto de pesquisa que está sendo desenvolvido por uma equipe multidisciplinar e se encontra na fase de avaliação do sistema de recomendação. A experiência tem como objetivo propor novos recursos tecnológicos para a construção de estratégias didático-pedagógicas voltadas ao ensino superior. Os objetos de aprendizagem, no presente estudo, são compreendidos como importantes recursos e conteúdos, sendo a base da recomendação.
\end{abstract}

Palavras-chaves: competência, sistemas de recomendação, objetos de aprendizagem.

\section{RECOMMENDING LEARNING OBJECTS BASED ON COMPETENCE IN DISTANCE LEARNING}

\begin{abstract}
This paper describes a model for recommending learning objects based on competence in Distance Learning. This model was designed based on experience obteined in the project of building a recommendation system for learning objects focusing on skills of teachers. The project is being developedb by a multidisciplinary team and is in the assessment phase of the recommendation system. It is an experience that aims to propose new technological resources for the construction of didactic and pedagogical strategies aimed at higher education. Learning objects are understood in this research as important resources and content, being the basis of the recommendation.
\end{abstract}

Keywords: competence, recommender systems, learning objects.

\footnotetext{
* Doutor em Ciência da Computação. Professor Adjunto e colaborador do Programa de pós-graduação em Ciência da Saúde, Universidade Federal de Ciência da Saúde de Porto Alegre, RS. E-mail: silvio.cazella@gmail.com

** Mestranda do Programa de Pós-Graduação em Informática na Educação, Universidade Federal do Rio Grande do Sul.

**** Doutora em Ciência da Computação. Professora do Programa de Pós-Graduação em Informática na Educação, Universidade Federal do Rio Grande do Sul.

***** Doutoranda do Programa de Pós-Graduação em Informática na Educação, Universidade Federal do Rio Grande do Sul.

****** Graduando do curso de Ciência da Computação, Universidade Federal do Rio Grande do Sul.
} 


\section{Introdução}

Neste artigo apresenta-se uma experiência desenvolvida pelo Núcleo de Tecnologia Digital Aplicada à Educação (NUTED ${ }^{1}$ ), vinculado a Universidade Federal do Rio Grande do Sul e que tem como objetivo o desenvolvimento de um modelo de recomendação de Objetos de Aprendizagem (OAs) através de competências voltadas para a Educação a Distância (EAD).

Desta forma, a proposta aqui apresentada tem por finalidade discutir os conceitos de sistemas de recomendação, objetos de aprendizagem e competências na EAD. Entende-se que, com o avanço tecnológico, novas concepções de ensino e aprendizagem emergiram assim como diferentes possibilidades de desenvolver conteúdos por meio de objetos de aprendizagem. Sabe-se que os OAs incorporados à aprendizagem on-line, tornam-se importantes recursos, já que oferecem acesso fácil às informações, possibilitando ao sujeito engajar-se de forma independente e autônoma para aprender por descoberta.

Portanto, um dos desafios do educador, ao deparar-se com novos conteúdos/recursos é a seleção e organização destes materiais, disponíveis na Internet, a fim de contemplar o perfil dos seus alunos e suas necessidades. Surgem, assim, os repositórios de objetos de aprendizagem, que são sistemas de busca que facilitam a ação de seleção e organização. Por outro lado, observa-se que os sistemas de busca acabam retornando muitos conteúdos irrelevantes, causando uma sobrecarga de resultados ao usuário.

Como solução a esta questão surgem os sistemas de recomendação que, de acordo com Cazella et al (2009) são sistemas que visam auxiliar o usuário na busca e seleção de um conteúdo focado em seu perfil, funcionando literalmente como filtros de informação.

Com o número de informações disponíveis, por vezes uma simples busca gera resultados irrelevantes e em muitos casos em grande quantidade ao usuário, não atendendo a necessidade real do mesmo.

Portanto, o sistema de recomendação, neste modelo, tem como finalidade filtrar os OAs por meio de competências contemplando perfis de alunos EAD. Corroborando a estes processos inovadores, o conceito de competência surge justamente no sentido de desenvolver novos conhecimentos, habilidades e atitudes ligadas ao uso das tecnologias.

Desta forma permitirá àqueles que participam da EAD se moldarem e adaptarem aos diferentes contextos e situações proporcionadas através do ensino e da aprendizagem online.

Neste sentido, este artigo descreve um modelo de um sistema de recomendação de OA com base no desenvolvimento de competências em EAD. O estudo encontra-se dividido da seguinte forma: na seção 2 são apresentados os sistemas de recomendação e objetos de aprendizagem, a seção 3 descreve o conceito de competência. A seção 4 apresenta uma breve descrição do projeto de pesquisa em andamento, a seção 5 apresenta 0 modelo proposto e por fim, a seção 6 descreve a conclusão.

\footnotetext{
${ }^{1}$ http://www.nuted.ufrgs.br/
} 


\section{Sistemas de recomendação e Objetos de Aprendizagem}

Com a quantidade de informações e com a disponibilidade facilitada das mesmas, pelo acesso a Internet, as pessoas deparam-se com uma diversidade muito grande de opções. Muitas vezes um indivíduo possui muito pouca ou quase nenhuma experiência pessoal para realizar escolhas entre as várias alternativas de conteúdos que lhe são apresentadas.

Os Sistemas de Recomendação auxiliam no aumento da capacidade e eficácia do processo de indicação já bastante conhecida na relação social entre seres humanos [CAZELLA et al, 2009]. Em um sistema típico de filtragem de informação, as pessoas fornecem recomendações como entradas e o sistema agrega e direciona para os indivíduos considerados potenciais interessados neste tipo de recomendação. Um dos grandes desafios deste tipo de sistema é realizar a combinação adequada entre as expectativas dos usuários (e seu perfil) e os produtos, serviços e pessoas a serem recomendados aos mesmos, ou seja, definir e descobrir este relacionamento de interesses é o grande problema. No contexto deste trabalho de pesquisa, pode-se vislumbrar um aluno sendo exposto a uma grande quantidade de objetos de aprendizagem (OA) que procuram auxiliá-lo em sua formação. Os Sistemas de Recomendação neste caso funcionam como filtros de informação encaminhando o objeto de aprendizagem que melhor atende o aluno frente as suas necessidades de aprendizado.

Segundo Wiley (2000), Objetos de Aprendizagem são pequenos componentes instrucionais que podem ser reutilizados inúmeras vezes em diferentes contextos de aprendizagem. Haughey e Muirhead (2005) apontam que existem diversas definições para o termo e que algumas se concentram na parte "objeto" do termo, enquanto outros têm enfatizado o aspecto da "aprendizagem". Os autores ressaltam que os OAs não têm valor ou utilidade fora dos contextos de ensino, seu valor está na sua aplicação às configurações de sala de aula e ambientes online onde os professores podem ou não estar presentes, [HAUGHEY e MUIRHEAD, 2005].

Os objetos de aprendizagem (OAs) também podem ser definidos como módulos ou unidades de conteúdo que podem ser utilizados para aprendizagem com apoio das tecnologias digitais [IEEE, 2002, p. 5, apud COLL; MONEREO, 2010, p. 252]. Tem como características a possibilidade de serem adaptados, reutilizados, acessíveis, duráveis, além de poderem ser utilizados em diferentes plataformas [FABRE et al., 2003, apud TAROUCO et al., 2004], tais como web, dispositivos móveis e TV digital. Esses recursos permitem que os OAs tenham seu uso ampliado, atingindo especialmente os professores de Educação Básica, que têm nos objetos um recurso importante para suporte ao trabalho pedagógico.

Neste trabalho de pesquisa, o modelo pretende recomendar, objetos de aprendizagem conforme as competências a serem desenvolvidas pelo usuário. A seção 3 descreve o conceito de competências.

\section{Competências para Educação a Distância}

O termo "competência" teve origem no âmbito jurídico, tratando de competência para julgar algo, uso ainda corrente. Aos poucos o termo foi inserindo-se na educação.

Primeiramente, foi utilizado em relação à qualificação e certificação, especialmente o ensino profissionalizante e técnico. O termo começou a ganhar força no campo empresarial, sendo bastante utilizado e explorado na literatura da área. $\mathrm{Na}$ 
educação, no final da década de 1990, houve um grande aumento tanto no interesse quanto na produção de artigos, livros, eventos e documentos sobre as competências. $\mathrm{O}$ tema tem sido explorado em associação a diferentes níveis e modalidades educacionais.

No entanto, essa área continua sofrendo resistências em razão da visão taylorista fordista que foi empregada às competências, principalmente na década de 1970. Porém, as competências, relacionadas a uma perspectiva construtivista, podem contribuir para uma formação integral do estudante, visto que enfatiza o desenvolvimento do sujeito e não a memorização de conteúdos. Entende-se que os conteúdos são necessários e, a partir deles, o sujeito constrói conhecimentos que correspondem a uma parte das competências, mas não traduzem a totalidade do conceito. As competências dependem do contexto, por isso tem um caráter dinâmico.

Le Boterf (2004) afirma que ser competente no séc. XXI não significa o mesmo que ser competente em 1950, em 1970 e, mesmo, em 1990. Isso porque, as mudanças tecnológicas, os acontecimentos sócio-históricos e culturais modificam o que é necessário ou relevante para aquele contexto diante dos novos desafios e situações problema.

Destaca-se que a perspectiva abordada neste artigo trata o termo "competência" no plural, pois se compreende que não existe apenas uma competência, mas sim diversas que são solicitadas em uma determinada situação. Tais competências são formadas por um conjunto de elementos, que correspondem ao conjunto de recursos que uma pessoa dispõe.

Segundo Perrenoud (1999), uma competência pressupõe a existência de recursos; nenhum recurso pertence, com exclusividade, a uma competência, na medida em que pode ser mobilizado por outras.

Assim, são três os elementos que compõem as competências, a saber: Conhecimentos, Habilidades e Atitudes (CHA). É necessário mobilizar atitudes, habilidades e conhecimentos ao mesmo tempo e de forma inter-relacionada.

Le Boterf (1995) propõe que a competência seja concebida como a capacidade de mobilizar um conjunto de recursos cognitivos para enfrentar uma situação complexa. Desse modo "a competência não reside nos recursos (conhecimentos, capacidades...) a serem mobilizados, mas na própria mobilização desses recursos. A competência pertence a ordem do "saber mobilizar". Assim a mobilização de recursos é a metáfora utilizada para exemplificar como os elementos do CHA se relacionam quando o sujeito se depara com uma nova situação. Perrenoud (2004) acrescenta que a mobilização não é apenas o "uso" ou "aplicação", mas também adaptação, diferenciação, integração, generalização ou especificação, combinação, orquestração, coordenação; em suma, um conjunto de operações mentais complexas, que, ao deslocá-las às situações, transformam os conhecimentos em vez de deslocá-los.

Os elementos das competências podem ser relacionados com os quatro pilares da Educação do séc. XXI [DELORS, 1996]: aprender a conhecer (conhecimento), aprender a fazer (habilidade), aprender a viver com os outros e aprender a ser (atitudes). Assim, diante de um cenário de constantes transformações, no qual a capacidade de aprender é fundamental, pois os conteúdos de hoje podem estar obsoletos até o final da formação do profissional [TAPSCOT, 2010], surge cada vez mais a necessidade do desenvolvimento de competências. Nessa perspectiva, o foco da aprendizagem não está apenas no conteúdo, mas também engloba os outros elementos do CHA. 
As competências estão vinculadas também a um domínio, por exemplo, de gestão, cognitivo, tecnológico e social. A idéia de domínio serve para agrupar as competências conforme suas características de forma a compreender melhor as relações entre elas.

Para a educação a distância, são consideradas competências básicas, a saber: organização, planejamento, relacionamento interpessoal, fluência digital, avaliação da aprendizagem, pedagógica, gestão acadêmica, administração do tempo, motivação, comunicação e reflexão. O desenvolvimento dessas competências requer constante aperfeiçoamento de estratégias educacionais, incluindo o uso de ferramentas tecnológicas.

Os objetos de aprendizagem poderão colaborar no desenvolvimento de elementos que compõem a(s) competência(s) ou da competência na sua totalidade (CHA) através dos desafios propostos. Nesse sentido, o recomendador de objetos de aprendizagem que está sendo construído pretende relacionar as competências, o perfil do usuário e os objetos cadastrados no repositório em questão.

\section{Recomendação de objetos de aprendizagem}

O objetivo principal do projeto é o desenvolvimento de um recomendador de conteúdos baseado em competências. A pesquisa tem envolvido estudos a cerca das competências e das possibilidades vinculadas ao processo de recomendação de objetos de aprendizagem.

Para realizar a avaliação do sistema de recomendação que está sendo desenvolvido, está sendo utilizado no $2^{\circ}$ semestre de 2011, o repositório de OA denominado CESTA $^{2}$ (Coletânea de Entidades de Suporte ao uso de Tecnologia na Aprendizagem), propondo a busca, seleção e recomendação de objetos de aprendizagem, com base nas competências.

O repositório CESTA é um projeto desenvolvido pelo Centro Interdisciplinar de Novas Tecnologias na Educação (CINTED) da Universidade Federal do Rio Grande do Sul (UFRGS) com o objetivo de catalogar, registrar e organizar objetos educacionais a fim de serem recuperados e reutilizados quando necessário.

A catalogação de OAs no CESTA é realizada através de um conjunto de metadados divididos em cinco categorias de especificação: geral, ciclo de vida, técnica, educacional e direitos. Este grupo de metadados foi constituído a partir das normas de padronização internacionais (IEEE P1484 - Leaning Objects Metadata) ${ }^{3}$. O desenvolvimento do Sistema de Recomendação está sendo realizado utilizando prototipação e tecnologia de software livre.

\section{Modelo de recomendação com base em competências}

Através dos estudos realizados foi concebido o Modelo de Recomendação com base em competências, conforme é apresentado na figura 1 a visão macro do modelo.

\footnotetext{
${ }_{2}{ }_{2}$ http://www.cinted.ufrgs.br/CESTA/

${ }^{3}$ IEEE (Institute of Electrical and Electronic Engineers) é responsável pelo padrão de metadados 1484.12.1

(Learning Objects Metadata) e agrupa em 9 (nove) categorias para descrição de um objeto educacional.
} 


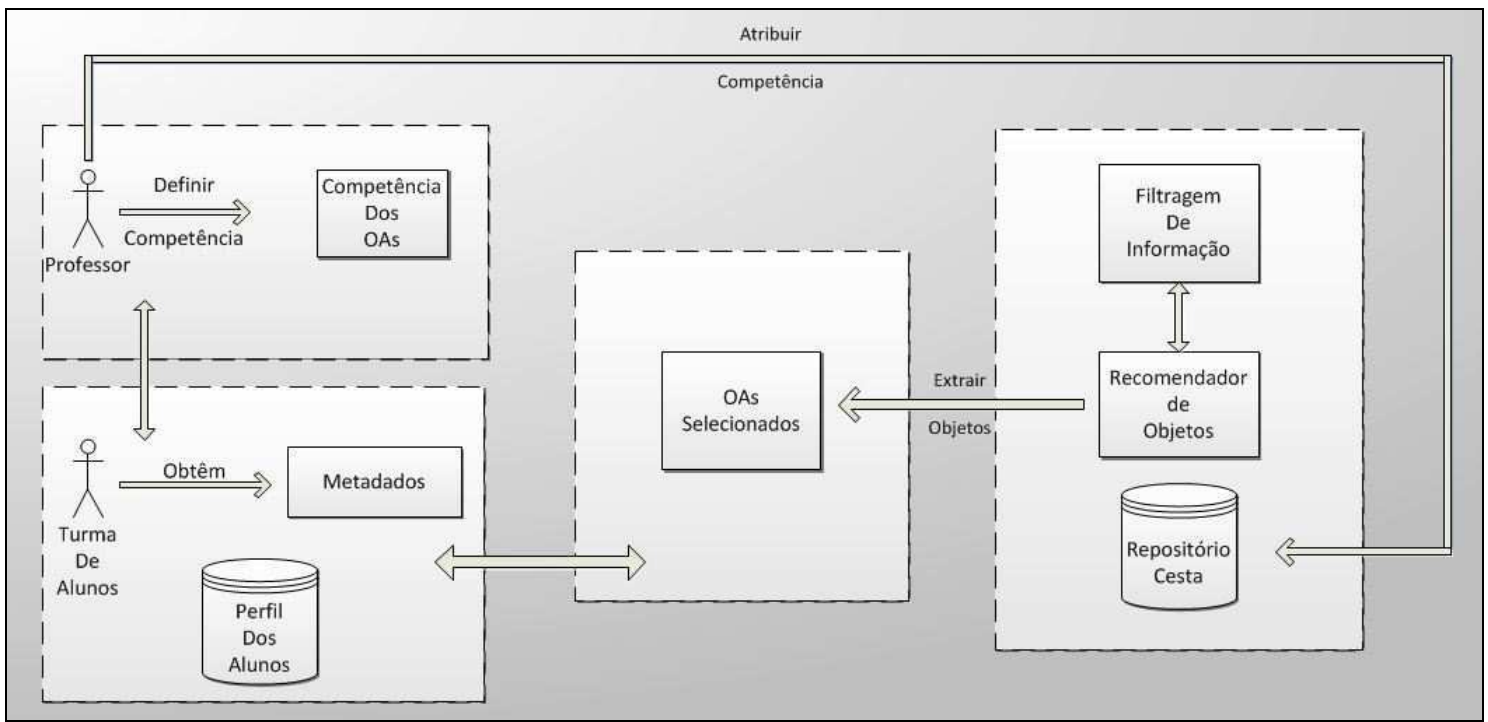

Figura 1 - Visão Macro do modelo

O funcionamento básico proposto pelo modelo constitui-se nas seguintes etapas:

1) O professor da disciplina seleciona quais objetos (provenientes do repositório

CESTA) irá utilizar com a sua turma visando o atingimento de competências específicas, e atribui aos mesmos as competências que estes suprem. Um objeto de aprendizagem pode atender mais de uma competência específica. Por exemplo, define que um Objeto de Aprendizagem hipotético "A" atende a competência "Tecnológica";

2) Os alunos respondem questionário padrão sobre o seu nível de conhecimento em competências que devem ser desenvolvidas ao longo da disciplina, e algumas informações demográficas específicas, para que o sistema possa recomendar os Objetos de Aprendizagem ;

3) Um mecanismo aciona a filtragem de informação, selecionando os Objetos de Aprendizagem a serem recomendados aos alunos, com base em seu perfil e as competências que o mesmo tem de desenvolver durante o curso. Estes objetos são selecionados diretamente do repositório CESTA através de seus metadados. Por exemplo: um Objeto de Aprendizagem foi concebido e em seu metadado está descrito que este objeto atende a competência "Tecnológica", desta forma caso o aluno precise desenvolver esta competência, o mesmo será recomendado ao aluno, como Objeto de Aprendizagem selecionado. A figura 2 apresenta as funcionalidades que estão sendo prototipadas com base no modelo descrito.

Para descrever as funcionalidades que constarão do protótipo, utilizamos o artefato da UML (Unified Modellig Language) conhecido como diagrama de caso de uso (ou use case). Este artefato constitui-se em um tipo de classificador representando uma unidade funcional coerente provida pelo sistema, subsistema, ou classe manifestada por seqüências de mensagens intercambiáveis entre os sistemas e um ou mais atores. Pode ser representado por uma elipse contendo, internamente, o nome do caso de uso [COCKBURN, 2005]. 


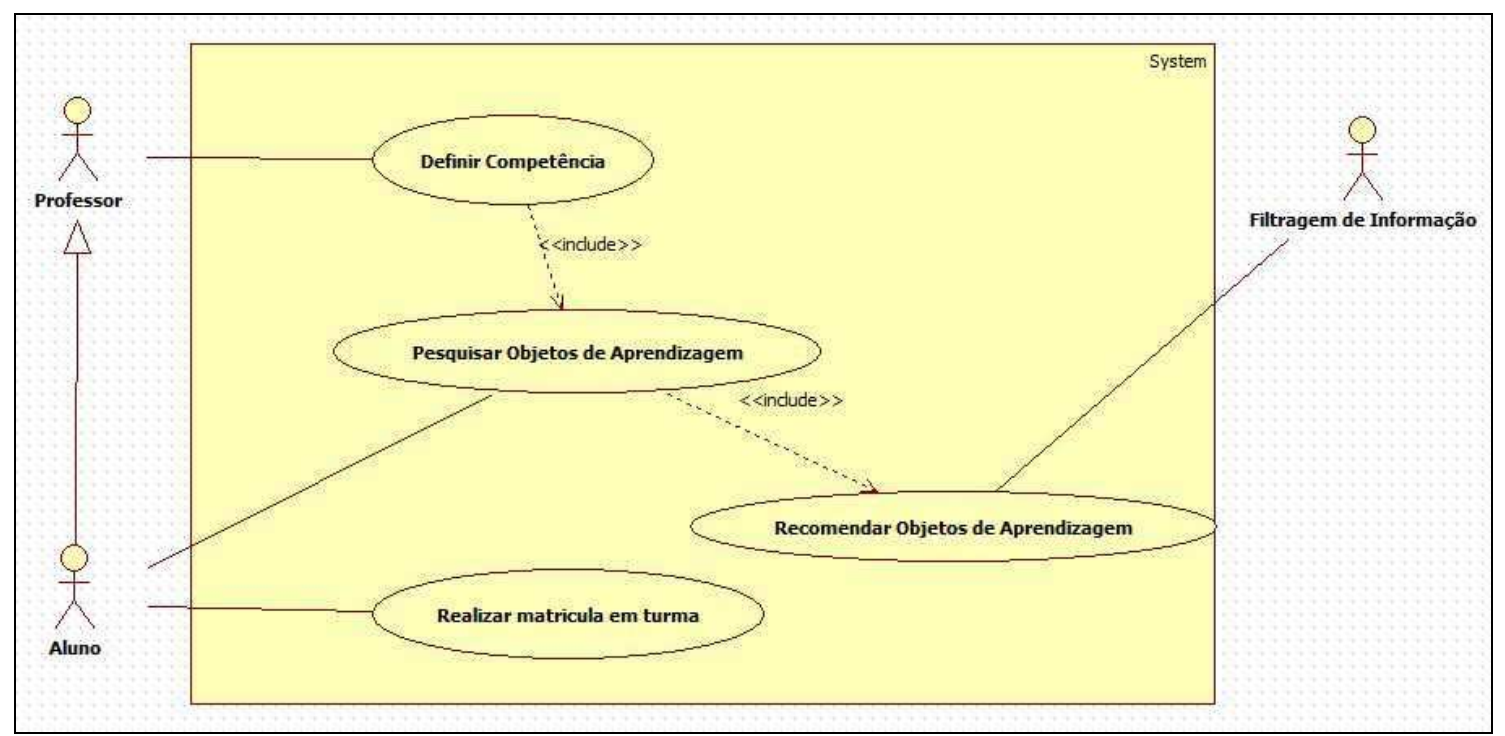

Figura 2 - Casos de Uso

No quadro 1, serão descritos os Casos de Uso que constam na figura 2.

Quadro 1 - Descrição de Casos de Uso (Use Cases)

\begin{tabular}{|l|}
\hline \multicolumn{1}{|c|}{ Casos de Uso (Use Cases) } \\
\hline Use Case: Definir Competência \\
Ator: Professor. \\
Fluxo de Eventos: \\
1) Professor atribui competência ou competências a serem supridas em aula. \\
2) Sistema procura em banco de dados objetos de aprendizagem que atendem as \\
competências. \\
Pós-Condições: \\
1) Lista de objetos de aprendizagem que suprem as competências definidas. \\
Casos de uso incluídos: \\
1) Pesquisar objetos de aprendizagem. \\
\hline Use Case: Pesquisar Objetos de Aprendizagem \\
Atores: Aluno \\
Pré-Condições: \\
1) Competência dos objetos de aprendizagem definida pelo professor. \\
Fluxo de Eventos: \\
1) Aluno tem acesso aos objetos de aprendizagem recomendados que potencialmente \\
atendem as suas necessidades frente às competências definidas. \\
2) Aluno adiciona a sua lista de objetos de aprendizagem os objetos recomendados para \\
estudo. \\
Casos de uso incluídos: \\
1) Recomendar Objetos de Aprendizagem \\
\hline Use Case: Recomendar Objetos de Aprendizagem \\
Ator: Filtragem de Informação \\
Pré-Condições: \\
1) Verifica se lista de objetos de aprendizado do aluno está cheia. \\
Fluxo de Eventos: \\
1) Analisa objetos de aprendizagem dos outros alunos. \\
2) Verifica objetos em comum entre os alunos da turma. \\
3) Recomenda objetos de aprendizado que o aluno teria interesse. \\
\hline Use Case: Realizar matricula em turma \\
\hline
\end{tabular}




\section{Ator: Aluno.}

Pré-condições:

1) Verificar se aluno já não se encontra matriculado na turma.

Fluxo de Eventos:

1) Matricular aluno em turma.

A figura 3, apresenta o diagrama de classes da solução proposta. Diagrama de classes constitui-se em um artefato que representa uma estrutura e relações das classes que representam os objetos (dentro do paradigma orientado a objetos). É uma modelagem muito útil para o sistema e define todas as classes (visão estática do sistema) que participam do mesmo [WAZLAWICK, 2011].

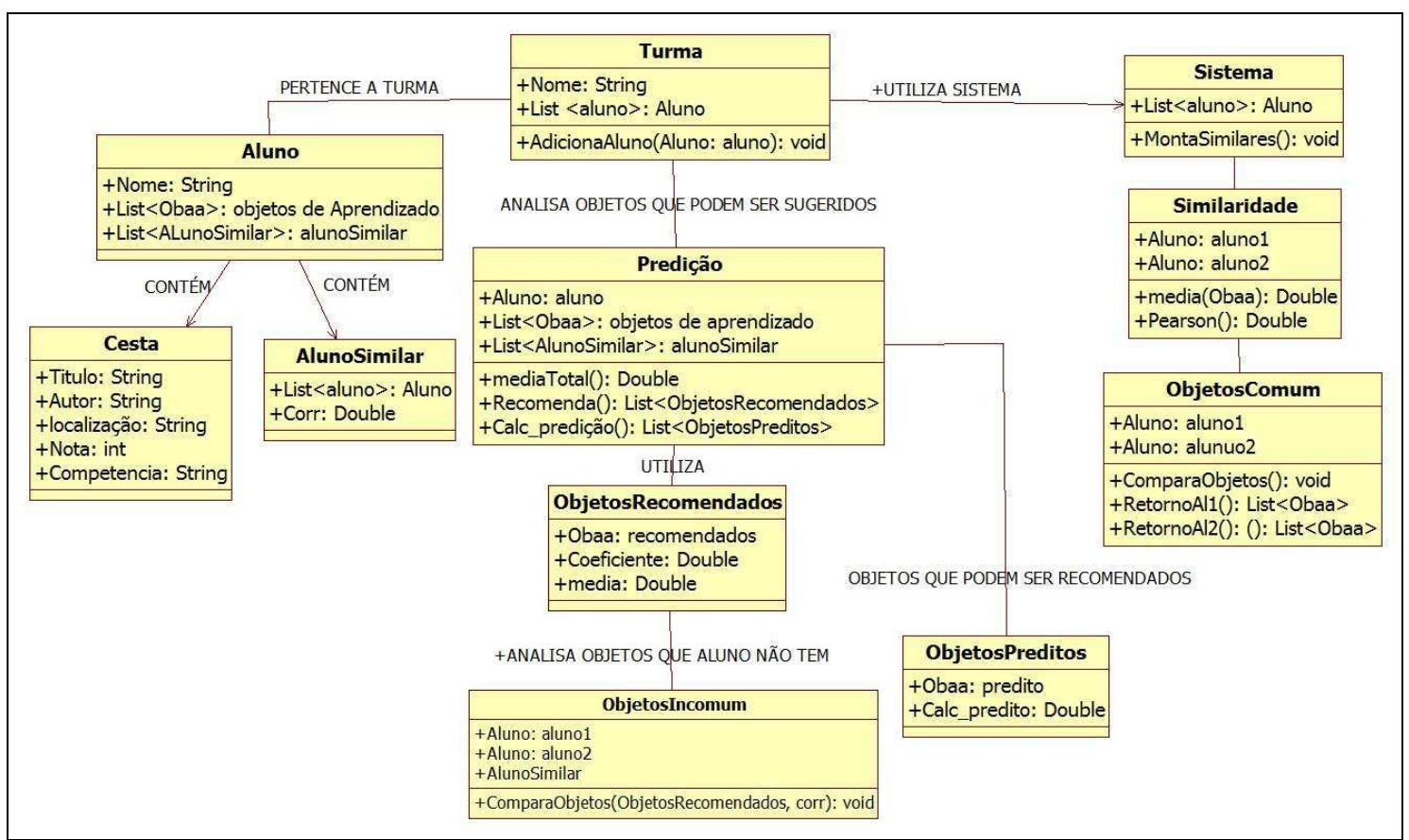

Figura 3 - Diagrama de Classe

No diagrama da figura 3, fica claro que a classe turma possui uma lista de alunos e cada aluno possui uma lista de OAs e uma lista de alunos que são similares a ele, quanto a maneira de avaliar conteúdo (Objetos de Aprendizagem). Em Sistemas de Recomendação entende-se que estes alunos possuem "gostos" em comum. Na solução implementada até o momento trabalha-se com Filtragem Colaborativa [CAZELLA et al, 2009], porém a solução final incluirá também a Filtragem Baseada em Conteúdo [CAZELLA et al, 2010]. A classe sistema utiliza a classe turma e verifica quais alunos são similares entre si, no que tange ao gosto pelos OAs. Através deste cálculo de similaridade que se faz possível a predição de se um aluno deve receber a recomendação do objeto de aprendizagem ou não. A classe predição recomenda os OAs, para os alunos que devem ser expostos aos OAs e precisam desenvolver as competências específicas.

As figuras 4 e 5 apresentam telas do protótipo desenvolvido com base no modelo definido, estas telas permitem que o professor defina as competências atendidas por um dado objeto de aprendizagem (Figura 4), e a figura 5, apresentará para o aluno, com base em seu perfil e competências a serem desenvolvidas, os objetos de aprendizado que o mesmo deverá acessar visando desenvolver competências específicas. 


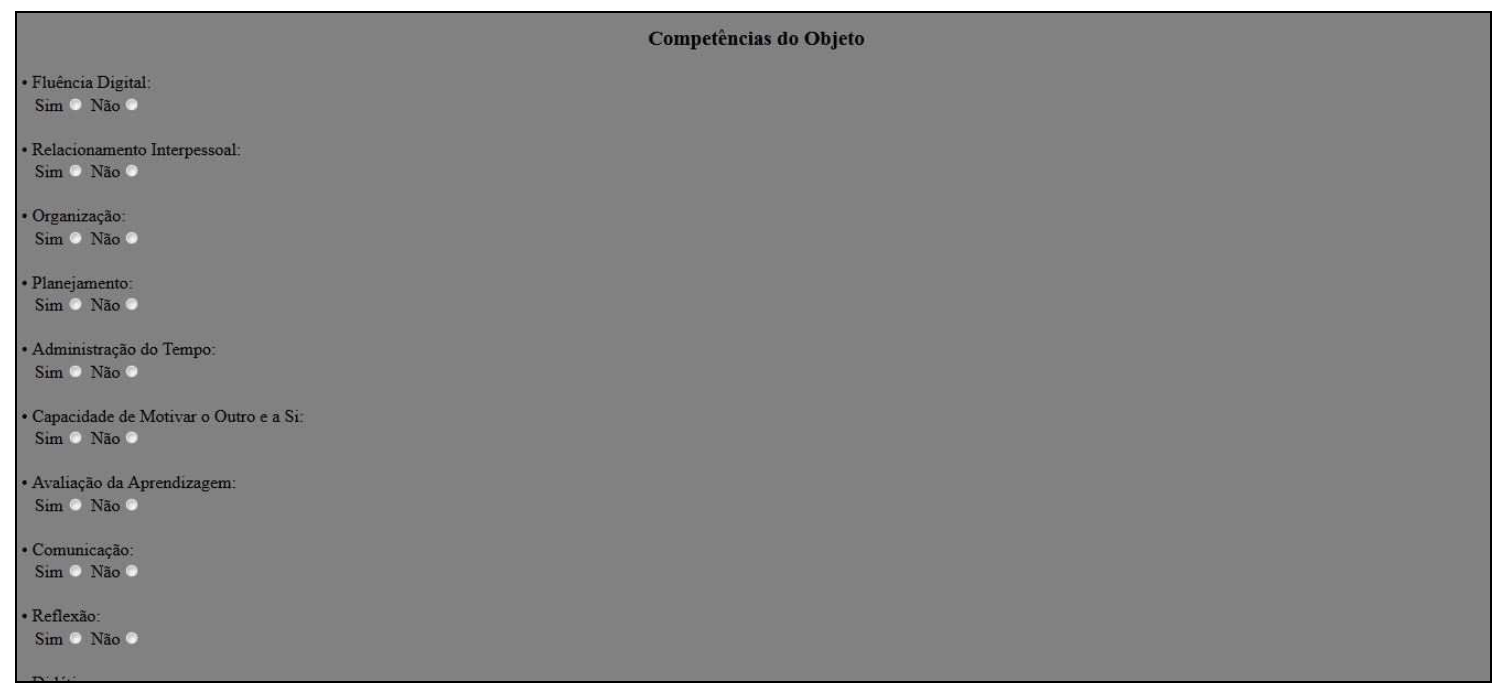

Figura 4 - Tela de cadastro de Competências

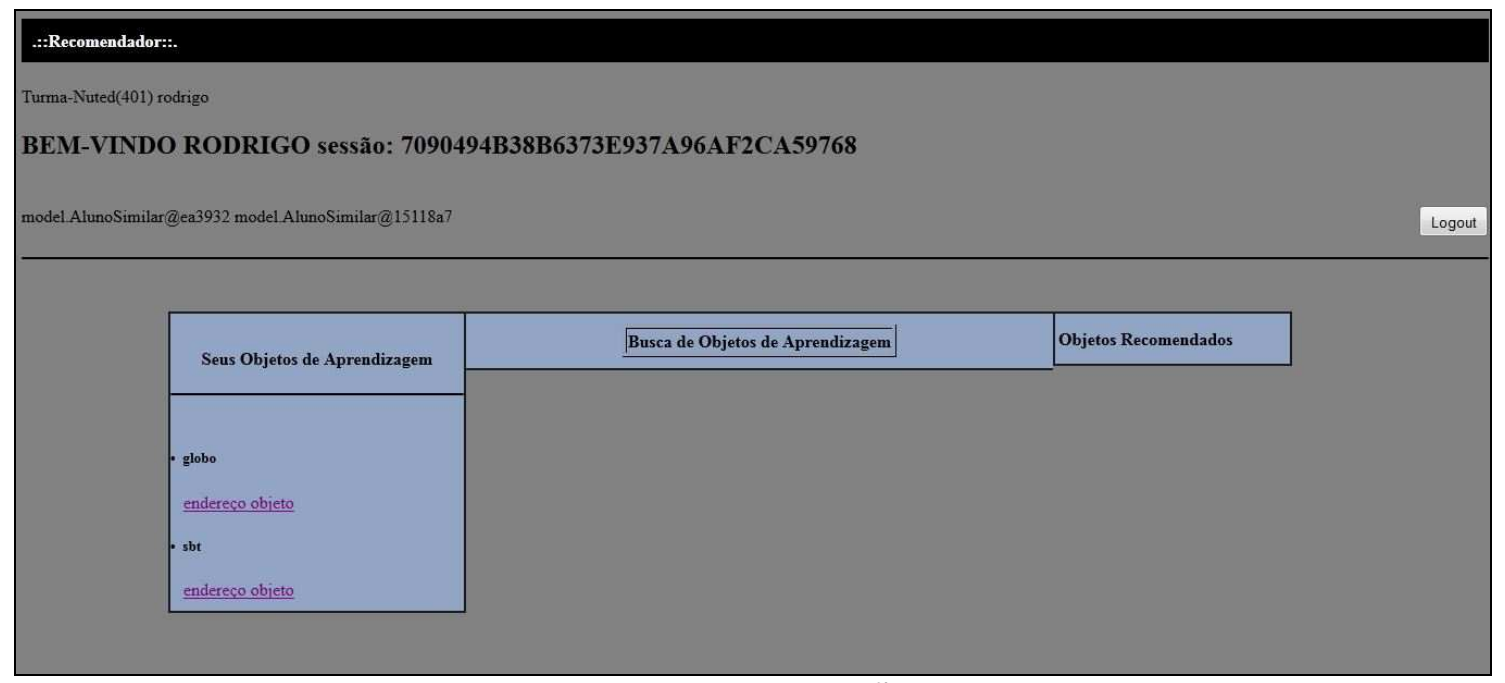

Figura 5 - Tela de recomendação de OAs

\section{Conclusão}

Este artigo apresentou um modelo para recomendação de objetos de aprendizagem baseado em competências para a EAD. A utilização de sistemas de recomendação permite que se encaminhe ao aluno o conteúdo (OA) que melhor atenda a sua necessidade de competência a ser desenvolvida.

A principal contribuição do modelo é a possibilidade de filtrar informações, no caso desta pesquisa, Objetos de Aprendizagem que melhor atendem as competências em EAD a serem desenvolvidas pelos alunos. Esta filtragem baseia-se no cruzamento do perfil do aluno e nas competências atribuídas ao Objeto de Aprendizagem. Nos experimentos e testes realizados até o momento junto ao protótipo verificou-se a eficiência da solução proposta utilizando dados sintéticos.

Como esta pesquisa encontra-se em andamento as conclusões aqui apresentadas não são finais, e a avaliação do sistema de recomendação está sendo realizada em uma turma de pós-graduação em Informática na Educação durante o $2^{\circ}$ semestre de 2011 . O repositório de OA denominado CESTA (Coletânea de Entidades de Suporte ao uso de Tecnologia na Aprendizagem), será a fonte dos OA e o sistema é software livre. 


\section{Referências}

Cazella, S. C. ; Reategui, E. ; Machado, M. ; Barbosa, J. (2009). Recomendação de Objetos de Aprendizagem Empregando Filtragem Colaborativa e Competências. In: Simpósio Brasileiro de Informática na Educação (SBIE), 2009, Florianópolis. XX Simpósio Brasileiro de Informática na Educação (SBIE), 2009.

Cazella, S. C. ; Drumm, J. ; Barbosa, J. . Um serviço para recomendação de artigos científicos baseado em filtragem de conteúdo aplicado a dispositivos móveis. RENOTE. Revista Novas Tecnologias na Educação, v. 8, p. 22, 2010.

Cockburn, A. (2005) Escrevendo Casos de Uso Eficazes. Porto Alegre: Artmed. 254p.

Coll, C; Monereo, C. (2010). Educação e aprendizagem no séc XXI: novas ferramentas, novos cenários, novas finalidades. In: Psicologia da Educação Virtual: Aprender e Ensinar com as Tecnologias da Informação e da Comunicação. Porto Alegre: Artmed.

Delors J. et al (1996) Educação um tesouro a descobrir: Relatório para a UNESCO da Comissão Internacional sobre Educação para o século XXI, Cortez, $1^{\text {a }}$ edição.

Haughey, M.; Muirhead, B. (2005) Evaluating learning objects for schools. Journal of Instructional Science and Technology, v.8, n.1, 2005. Disponível em: $<$ http://www.usq.edu.au/electpub/eist/docs/vol8_no1/fullpapers/eval_learnobjects_scho ol.htm>. Acesso em: abr. 2011.

Le Boterf, Guy. (2004) Construire les compétences - individuelles et collectives, 3e édition. Paris, Éditions d'Organization.

Perrenoud, P. (1999). Construir as competências desde a escola, Artmed, 1999, $1^{\mathrm{a}}$ edição.

Perrenoud, P. (2004) De uma metafora a outra: transferir ou mobilizar conhecimentos?In: DOLZ, Joaquim; OLLAGNIER, Edmee (Org.). O enigma da competência em educação. Porto Alegre: Artmed, 2004.

Tapscot, D. (2010) A hora da geração digital: como os jovens que cresceram usando a internet estão mudando tudo, das empresas aos governos, Agir Negócios, $1^{a}$ edição.

Tarouco, L. M. R. et al. (2004) Objetos de Aprendizagem para M-Learning. In: Congresso Nacional de Tecnologia da Informação e Comunicação (SUCESU). Florianópolis. Anais do Congresso Nacional de Tecnologia da Informação e Comunicação. Florianópolis, 2004. Disponível em: $\langle$ http://www.cinted.ufrgs.br/CESTA/objetosdeaprendizagem_sucesu.pdf $>$. Acesso em: 07 set. 2006.UNESCO (2008) ICT competency standards for teachers: policy framework. Paris.

Wazlawick, R. S. (2011) Análise e projeto de sistemas de informação orientados a objetos. Série SBC, Sociedade Brasileira de Computação.

Wiley, D. A. (2000) Connecting learning objects to instructional design theory: A definition, a metaphor, and a taxonomy. In: (Ed.). The Instructional Use of

Learning Objects: Online Version, 2000. Disponível em: <http://reusability.org/read/chapters /wiley.doc>. 